\title{
Social Media: The Good, the Bad, and the Ugly
}

\author{
Yogesh K. Dwivedi ${ }^{1} \cdot$ Gerald Kelly $^{2} \cdot$ Marijn Janssen $^{3} \cdot$ Nripendra P. Rana $^{1} \cdot$ Emma L. Slade $^{4} \cdot$ Marc Clement $^{5}$ \\ Published online: 22 March 2018 \\ (C) Springer Science+Business Media, LLC, part of Springer Nature 2018
}

The ubiquity of social media has had a profound effect on the way we communicate and is of significant importance to society and business. Social media tools have helped break down geographical barriers that once restricted communication and have led to an explosion of e-participation, virtual presence, and online communities. Professional benefits of social media include sharing of information, publicity, and giving and receiving support and advice (AlAlwan et al. 2017; Dwivedi et al. 2015, 2017a; Kapoor and Dwivedi, 2015; Kapoor et al. 2016; Mills et al. 2009; Plume et al. 2016). Consumers have become increasingly empowered to exert an influence on brands through online communities, while businesses are able to acquire rapid feedback and garner insight into individual preferences without observer effects

Yogesh K. Dwivedi

y.k.dwivedi@swansea.ac.uk

Gerald Kelly

Gerald.Kelly@sony.com

Marijn Janssen

M.F.W.H.A.Janssen@tudelft.nl

Nripendra P. Rana

n.p.rana@swansea.ac.uk

Emma L. Slade

emma.slade@bristol.ac.uk

Marc Clement

R.M.Clement@swansea.ac.uk

1 Emerging Markets Research Centre (EMaRC), School of Management, Swansea University, Swansea, Wales SA1 8EN, UK

2 Sony UK Technology Centre, Pencoed Technology Park, Bridgend, Wales CF35 5HZ, UK

3 Faculty of Technology, Policy and Management, Delft University of Technology, Delft, The Netherlands

4 School of Economics, Finance and Management, University of Bristol, Queen's Avenue, Bristol BS8 1SN, UK

5 School of Management, Swansea University, Bay Campus, Fabian Way, Swansea, Wales SA1 8EN, UK
(AlAlwan et al. 2017; Ismagilova et al. 2017; Kapoor et al. 2016; Plume et al. 2016) and use such data for new product development (Rathore et al. 2016). Social media tools also enable citizens to share advice and information with their local community (Oh et al., 2013), from promoting events to searching for lost pets, and aids government engagement with citizens (Alryalat et al. 2017).

The radical transformation of communication that has been enabled by social media presents a fascinating environment for academics from all backgrounds. People browse and contribute to their social media accounts regularly using smart devices; some people even prefer to communicate using social media rather than participating in face-to-face interaction. Yet communication using social media might be more challenging as emotions can be difficult to detect and comprehend. Furthermore, the anonymity granted through social media facilitates harmful and socially unacceptable behaviours such as cyberbullying.

The volume of valuable datasets available through social media applications has led to the emergence of automated techniques and systems that can analyse the 'big data' generated. Analytics help businesses to ensure their social media activities are adding value and helping to accomplish business goals. Analysis of social media content can also help to safeguard society from organized crime but such uses remain a delicate issue. There are also risks of using social media analysis in terms of generalizability, as people might prefer different social media or refrain from social media entirely, which could result in bias and even drawing of the wrong conclusions.

With seemingly endless benefits it is easy to overlook the disadvantages of social media, which are an increasingly important consideration as social media platforms continue to proliferate. Social media has facilitated a loss of ownership and control of content as private, public and institutional domains progressively overlap. There is a need for careful balancing of professionalism and freedom of speech to ensure that posts do not cause offence or harm reputations. The quality of social media content is diverse, ranging from facts to 'fake news'. Inaccurate information can spread around the 
world within a very short time and influence perceptions and opinions of people negatively. Other drawbacks include time pressure, plagiarism, misrepresentation, addiction, and negative psychological consequences. While providing a means to protect public safety, social media also provides a means of threatening it and enabling new forms of cyber-crime and even cyberwarfare. Social media has also been used by terrorists for opportunistic decision making in volatile and extreme environments (Oh et al. 2011). Considering the threat posed by social media for security and safety, now governments of some countries, such as South Korea, are starting to introduce Internet surveillance (Kwon \& Rao, 2017).

This special issue of ISF aimed to bring together a variety of disciplines and a community for the advancement of knowledge regarding the adoption, use, impact, and potential of social media. To achieve this goal, literature review, theoretical and empirical papers employing quantitative and/or qualitative methods were welcomed for consideration. The nine articles accepted for inclusion in this special issue are briefly summarised below; they have examined a diverse range of issues related to social media by employing either qualitative, quantitative, analytical or theoretical approaches.

The first three articles of this special issue have adopted a qualitative approach to examine issues of self-disclosure (Richey et al. 2018), organisational competitiveness (Kwayu et al. 2018), and tackling and improving Big Data of variable data quality (Wahyudi et al. 2018).

Richey et al.'s article (The Perils and Promises of SelfDisclosure on Social Media) adopted the dramaturgical vocabulary of Goffman (1959) to shed light on how individuals cope with increased levels of self-disclosure on social media. This study argues that self-presentations of professionals on social media can be likened to post-modern performances in which the traditional boundaries between actor and audience are intentionally unsettled. These casual posts communicate additional personal traits that are not otherwise included in professional presentations. Since there are no strict boundaries between formal front-stage and relaxed back-stage regions in these types of performance, a liminal mental state is often used, which enables a better assessment of the type of information to present on social media (Richey et al. 2018).

Kwayu et al.'s article (Enhancing Organisational Competitiveness Via Social Media - a Strategy as Practice Perspective) argues that the affordances, popularity and pervasive use of social media platforms such as Facebook, Twitter and Instagram have made these platforms attractive to organisations for enhancing their competitiveness and creating business value. Despite this apparent significance of social media for businesses, they are struggling with the development of a social media strategy as well as understanding the implications of social media on practice within their organisations. Considering the above arguments as a basis, this article explored how social media has become a tool for competitiveness and its influence on organisational strategy and practice. The study utilised the 'strategy as practice' lens and an interpretivist approach for conducting an empirical case of a telecom organisation in Tanzania. The results of this study show that social media is having an impact on competitiveness through imitation and product development. The results reported in this study also suggest how social media affects the practices within an organisation, consequently making the social media strategy an emergent phenomenon (Kwayu et al. 2018).

In Wahyudi et al.'s article, entitled "A Process Pattern Model for Tackling and Improving Big Data of Variable Data Quality", the authors argue that social media data seldom create value by themselves. Social media data need to be linked and combined from multiple sources, which often have variable data quality. Many organizations are struggling to improve the data quality and the tasks of improving the quality of social media data is a recurring challenge. For this, a practical situation is analyzed to derive patterns for improving data quality. A process pattern model is defined by the authors as a proven series of activities, aimed at improving the data quality given a certain context, a particular objective, and a specific set of initial conditions. Four different patterns to deal with the variations in data quality of datasets have been identified in this study. Instead of having to find a way to improve the quality of big data for each situation, the process model (presented in this study) provides data users with generic patterns, which can be used as a reference model to improve big data quality (Wahyudi et al. 2018).

The next three studies of this special issue have adopted a survey based quantitative approach to explore the sharing of sponsored advertisements (Plume and Slade al. 2018), sharing political content (Hossain et al. 2018), and impact of social media on consumers' acculturation and purchase intentions (Kizgin et al. 2018).

Plume and Slade (Sharing of Sponsored Advertisements on Social Media: A Uses and Gratifications Perspective) employed Uses and Gratifications theory to determine salient motivations for users' intentions to share sponsored advertisements in the tourism context. Analysis of survey data $(n=487)$ revealed that altruism, entertainment, socialising, and information seeking are the significant positive drivers of intention to share tourism related sponsored advertisements on Facebook. Notably, information sharing was found to have a negative effect, while selfexpression had no significant effect. Results also determined that there were no significant differences in motivations between males and females (Plume and Slade 2018).

In Hossain et al.'s article (Sharing Political Content in Online Social Media: A Planned and Unplanned Behaviour Approach) the authors empirically examined factors related to planned and unplanned behaviour to understand why people share political content in online social media. Based on an online survey of 257 social media users, results of this study demonstrate that the 
factors representing both planned (i.e., perceived social recognition and altruistic motivation) and unplanned behaviour (i.e., extroversion and impulsiveness) affect people's political content sharing behaviour. This study argues that sharing political content is not like sharing other forms of content such as tourist attractions as the former can provoke serious punishment in some countries. The study also found that the trait 'impulsiveness' is negatively associated with political content sharing behaviour. It is also found that collective opinion moderates people's planned behaviour but not their unplanned behaviour, which means that the personality traits are unaffected by others' opinions, but traits that humans can control can be shaped by others (Hossain et al. 2018).

Kizgin et al. ("The Impact of Social Media on Consumers' Acculturation and Purchase Intentions") argue that social media has emerged as a significant and effective means of assisting and endorsing activities and communications among peers, consumers and organizations that outdo the restrictions of time and space. Based on review of existing literature, this article suggests that while some of the existing work on social media has acknowledged the role of agents of culture change, there is still a lack of understanding regarding the role of social media in influencing acculturation outcomes and consumption choices. This study employed a self-administered questionnaire to collect data from 514 Turkish-Dutch respondents to examine how their use of social media affects their acculturation and consumption choices. The results suggest that social media is a vital means of culture change and a driver of acculturation strategies and consumption choices (Kizgin et al. 2018).

The next article by Aswani et al., entitled "Detection of Spammers in Twitter Marketing: A Hybrid Approach Using Social Media Analytics and Bio Inspired Computing", employed an analytical approach. The authors proposed a hybrid approach for identifying spam profiles by combining social media analytics and bio inspired computing. The study adopted a modified K-Means integrated Levy Flight Firefly Algorithm (LFA) with chaotic maps as an extension to Firefly Algorithm (FA) for spam detection in Twitter marketing. The study analysed a total of 18,44,701 tweets from 14,235 Twitter profiles on 13 statistically significant factors that were derived from social media analytics. A Fuzzy C-Means Clustering technique was used to identify the overlapping users in two clusters of spammers and non-spammers. Six variants of KMeans integrated FA including chaotic maps and levy flights were tested. The results of this study suggest that FA with chaos for tuning attractiveness coefficient using Gauss Map converges to a working solution the fastest. Further, LFA with chaos for tuning the absorption coefficient using sinusoidal map outperforms the rest of the approaches in terms of accuracy (Aswani et al. 2018).

The final two studies (Kapoor et al. 2018; Muhammad et al. 2018) in this special issue are exhaustive reviews of existing literature focussed on digital and social media.
The article by Kapoor et al. (Advances in Social Media Research: Past, Present and Future), discusses the findings of 132 papers (published in selected IS journals between 1997 and 2017) on social media and social networking sites. Most papers reviewed in this article examined the behavioural side of social media, investigated the aspect of reviews and recommendations, and explored integration of social media for organizational purposes. The review revealed that existing studies on social media have also investigated the viability of online communities/social media as a marketing medium and have explored various aspects of social media, including the risks associated with its use, the value that it creates, and the negative stigma attached to it within workplaces. The use of social media for information sharing during critical events as well as for seeking and/or rendering help has also been investigated in prior research. Other contexts include political and public administration, and the comparison between traditional and social media. This work also identified theories and models (such as social role theory, game theory, structural holes theory, management and commitment theories, institutional theory, deterrence and mitigation theories, and self determination and self categorization theories) in social media research as well as noted that widely utilised IS/IT adoption theories such as Unified Theory of Acceptance and Use of Technology (Dwivedi et al. 2017b, c; Venkatesh et al. 2003), Technology Acceptance Model (Davis 1989) and Innovation Diffusion Theory (Kapoor et al. 2014a,b) are less widely utilised. Overall, this review article has identified multiple emergent themes in the existing corpus. The integrated view of the extant literature that this study has presented can help avoid duplication by future researchers, whilst offering fruitful lines of enquiry to help shape research for this emerging field (Kapoor et al. 2018).

The second review article by Muhammad et al., entitled "Analysis of Factors that Influence Customers' Willingness to Leave Big Data Digital Footprints on Social Media: a Systematic Review of Literature", conducted a systematic review of extant literature (published between 2002 to 2017) to identify and analyse the underlying factors that influence customers' willingness to leave digital footprints on social media. The main outcome from this review is the conclusion that personal behaviour (intrinsic psychological dispositions), technological factors (relative advantage and convenience), social influence (social interaction, social ties and social support) and privacy and security (risk, control and trust) are the key factors that influence customers' willingness to generate and leave big data digital footprints on social media. The conceptual framework presented in this paper is likely to advance the scholarship of technology adoption and use, and provides useful directions for future empirical research for both academics and practitioners (Muhammad et al. 2018).

This special issue has evolved from research presented during the WG 6.11 15th IFIP e-Business, e-Services, and eSociety (I3E) Conference which was hosted at the School of Management, Swansea University, UK in September 2016. 
The conference invited the following two types of submissions: full-length research papers and short papers for 'research in progress'. The call for papers attracted more than 100 submissions, representing a broad international crosssection of authors. These submissions were reviewed rigorously by at least two independent reviewers which resulted in selection of the final set of papers that appeared in the blind peer-review conference proceedings. Further detail about the content of the conference proceedings can be found in Dwivedi et al. (2016).

Five papers were selected from the I3E2016 conference for consideration for publication in this special issue of Information Systems Frontiers. The following guidelines were used for selection of these articles. We identified a set of papers with substantial empirical content and theoretical contribution that represented the range of issues bearing on the conference theme. The results of the peer-review process for the conference influenced our selection decisions. Initially, authors of shortlisted papers were provided with feedback outlining suggestions for improving and extending their papers. The revised and substantially extended versions were submitted online, and each submission went through two-tothree rounds of further reviews involving three reviewers each. The remaining four papers included in this special issue were submitted in response to an open call for papers. These papers were also subjected to two-to-three rounds of reviews involving three reviewers each.

Acknowledgments We would like to thank the Chief Editors, Prof. H. Raghav Rao and Prof. Ram Ramesh, of Information Systems Frontiers for providing the opportunity to organize this special issue. The guest editors also gratefully acknowledge the support of referees who reviewed the manuscripts submitted for possible publication in this special issue.

\section{References}

AlAlwan, A., Rana, N. P., Dwivedi, Y. K., \& Algharabat, R. (2017). Social Media in Marketing: A review and analysis of the existing literature. Telematics and Informatics, 34(7), 1177-1190.

Alryalat, M., Rana, N. P., Sahu, G. P., Dwivedi, Y. K., \& Tajvidi, M. (2017). Use of social Media in Citizen-Centric Electronic Government Services: A literature analysis. International Journal of Electronic Government Research, 13(3), 55-79.

Aswani, R., Kar, A. K., \& Ilavarasan, P. V. (2018). Detection of spammers in twitter marketing: A hybrid approach using social media analytics and bio inspired computing. Information Systems Frontiers, 20(3). https://doi.org/10.1007/s10796-017-9805-8.

Davis, F. D. (1989). Perceived usefulness, perceived ease of use, and user acceptance of information technology. MIS Quarterly, 13(3), 318339.

Dwivedi Y.K., Mäntymäki M., Ravishankar M.N., Janssen M., Clement M., Slade E.L., Rana N.P., Al-Sharhan S., \& Simintiras A.C. (Eds.) (2016). Social media: The good, the bad, and the ugly. 15th IFIP WG 6.11 Conference on e-Business, e-Services, and e-Society, I3E 2016, Swansea, UK, September 13-15, 2016, proceedings (Vol. 9844).
Dwivedi, Y. K., Kapoor, K. K., \& Chen, H. (2015). Social media marketing and advertising. The Marketing Review, 15(3), 289-309.

Dwivedi, Y. K., Rana, N. P., \& Alryalat, M. (2017a). Affiliate marketing: An overview and analysis of emerging literature. The Marketing Review, 17(1), 33-50.

Dwivedi, Y. K., Rana, N. P., Jeyaraj, A., Clement, M., \& Williams, M. D. (2017b). Re-examining the unified theory of acceptance and use of technology (UTAUT): Towards a revised theoretical model. Information Systems Frontiers. Available at. doi:https://doi.org/10. 1007/s10796-017-9774-y.

Dwivedi, Y. K., Rana, N. P., Janssen, M., Lal, B., Williams, M. D., \& Clement, M. (2017c). An empirical validation of a unified model of electronic government adoption (UMEGA). Government Information Quarterly, 34(2), 211-230.

Hossain, M. A., Dwivedi, Y. K., Chan, C., Standing, C., \& Olanrewaju, A. S. (2018). Sharing political content in online social media: A planned and unplanned behaviour approach. Information Systems Frontiers, 20(3). https://doi.org/10.1007/s10796-017-9820-9.

Ismagilova, E., Dwivedi, Y. K., Slade, E. L., \& Williams, M. D. (2017). Electronic word of mouth (eWOM) in the marketing context: A state of the art analysis and future directions. Springer International Publishing.

Kapoor, K. K., Tamilmani, K., Rana, N. P., Patil, P., Dwivedi, Y. K., \& Nerur, S. (2018). Advances in social media research: Past, present and future. Information Systems Frontiers, 20(3). https://doi.org/10. 1007/s10796-017-9810-y.

Kapoor, K. K., Dwivedi, Y. K., \& Piercy, N. (2016). Pay-per-click advertising: A literature review. The Marketing Review, 16(2), 183-202.

Kapoor, K. K., \& Dwivedi, Y. K. (2015). Metamorphosis of Indian electoral campaigns: Modi's social media experiment. International Journal of Indian Culture \& Business Management, 11(4), 496-516.

Kapoor, K. K., Dwivedi, Y. K., \& Williams, M. D. (2014a). Innovation adoption attributes: A review and synthesis of research findings. European Journal of Innovation Management, 17(3), 327-348.

Kapoor, K. K., Dwivedi, Y. K., \& Williams, M. D. (2014b). Rogers' innovation adoption attributes: A systematic review and synthesis of existing research. Information Systems Management, 31(1), 74-91.

Kizgin, H., Jamal, A., Dey, B. L., \& Rana, N. P. (2018). The impact of social media on consumers' acculturation and purchase intentions. Information Systems Frontiers, 20(3). https://doi.org/10.1007/ s10796-017-9817-4.

Kwon, K. H., \& Rao, H. R. (2017). Cyber-rumor sharing under a homeland security threat in the context of government internet surveillance: The case of South-North Korea conflict. Government Information Quarterly, 34(2), 307-316.

Kwayu, S., Lal, B., \& Abubakre, M. (2018). Enhancing Organisational competitiveness via social media - a strategy as practice perspective. Information Systems Frontiers, 20(3). https://doi.org/10.1007/ s10796-017-9816-5.

Mills, A., Chen, R., Lee, J., \& Raghav Rao, H. (2009). Web 2.0 emergency applications: How useful can twitter be for emergency response? Journal of Information Privacy and Security, 5(3), 3-26.

Muhammad, S. S., Dey, B. L., \& Weerakkody, V. (2018). Analysis of factors that influence customers' willingness to leave big data digital footprints on social media: A systematic review of literature. Information Systems Frontiers, 20(3). https://doi.org/10.1007/ s10796-017-9802-y.

Oh, O., Agrawal, M., \& Rao, H. R. (2013). Community intelligence and social media services: A rumor theoretic analysis of tweets during social crises. MIS Quarterly, 37(2), 407-426.

Oh, O., Agrawal, M., \& Rao, H. R. (2011). Information control and terrorism: Tracking the Mumbai terrorist attack through twitter. Information Systems Frontiers, 13(1), 33-43.

Plume, C. J., \& Slade, E. L. (2018). Sharing of sponsored advertisements on social media: A uses and gratifications perspective. Information Systems Frontiers, 20(3). https://doi.org/10.1007/s10796-017-9821-8. 
Plume, C. J., Dwivedi, Y. K., \& Slade, E. L. (2016). Social Media in the Marketing Context: A state of the art analysis and future directions (1st ed.). Oxford, UK: Chandos Publishing Ltd.

Rathore, A. K., Ilavarasan, P. V., \& Dwivedi, Y. K. (2016). Social media content and product co-creation: An emerging paradigm. Journal of Enterprise Information Management, 29(1), 7-18.

Richey, M., Gonibeed, A., \& Ravishankar, M. N. (2018). The perils and promises of self-disclosure on social media. Information Systems Frontiers, 20(3). https://doi.org/10.1007/s10796-017-9806-7.

Venkatesh, V., Morris, M. G., Davis, G. B., \& Davis, F. D. (2003). User acceptance of information technology: Toward a unified view. MIS Quarterly, 27(3), 425-478.

Wahyudi, A., Kuk, G., \& Janssen, M. (2018). A process pattern model for tackling and improving big data quality. Information Systems Frontiers, 20(3). https://doi.org/10.1007/s10796-017-9822-7.

Yogesh K. Dwivedi is a Professor of Digital Marketing and Innovation, Dean of Academic Leadership (REF Research Environment and Interdisciplinary Research), and Director of the Emerging Markets Research Centre (EMaRC) in the School of Management at Swansea University, Wales, UK. His research interests are at the interface of Information Systems (IS) and Marketing, focusing on issues related to consumer adoption and diffusion of emerging ICT-based applications, electronic/digital government, and digital marketing particularly in the context of emerging markets. He has published more than 250 articles in a range of leading academic journals and conferences. He has coedited/co-authored more than 20 books on technology adoption, e-government, IS theory, eWOM and social media which have been published by international publishers such as Chandos Publishing (an imprint of Elsevier), Springer, Chapman and Hall/CRC Press, Routledge and Emerald. He has acted as co-editor of 19 journal special issues; organised tracks, mini-tracks and panels in leading conferences; and served as Programme Co-Chair of the 2013 IFIP WG 8.6 Conference on Grand Successes and Failures in IT: Public and Private Sectors and as Conference Chair of the IFIP WG 6.11 I3E2016 Conference on Social Media: The Good, the Bad, and the Ugly. He is an Associate Editor of the European Journal of Marketing and Government Information Quarterly and Senior Editor of the Journal of Electronic Commerce Research. Professor Dwivedi is the founding editor of the recently established Springer Book Series on Advances in Theory and Practice of Emerging Markets (http://www.springer.com/series/15802). More information about Professor Dwivedi can be found at: http://www.swansea.ac.uk/ staff/som/academic-staff/y.k.dwivedi/

Gerald Kelly is a Company Director for Sony Europe and is based at the Sony UK Technology Centre in Pencoed, South Wales. Gerald's primary responsibility as Director of Professional Services is human resources, new business development, IS, public relations, site management and business control. Gerald also has a concurrent role as an Executive Board member, supporting the development of, and the execution of strategic activities which underpin the growth and sustainability of the business. Gerald has been with Sony for over 35 years and has extensive experience in Equipment Engineering, Manufacturing Management and Business Support functions prior to his current assignments. Gerald trained as a mechanical engineer with BP oil and has also worked for ALCOA GB prior to joining the team at Sony. He is married with four children and is currently researching for a MSc with Swansea University. His research is examining the growth and potential future growth of the Life Science technology product sector and in parallel the identification of a sustainable 3rd party manufacturing business model that could support and sustain the identified life science technology product growth in the UK
Marijn Janssen is full Professor in ICT \& Governance and head of the Information and Communication Technology research group of the Technology, Policy and Management Faculty of Delft University of Technology. His research interests are in the field of orchestration, (shared) services, intermediaries, open and big data and infrastructures within constellations of public and private organizations. He was involved in several EU funded projects (a.o. EGovRTD2020, eGovPoliNet, Engage) and is involved in H202 VRE4EIC and OpenGovIntelligence. He is Co-Editor-in-Chief of Government Information Quarterly (GIQ) and Associate Editor of the International Journal of Electronic Business Research (IJEBR), Electronic Journal of eGovernment (EJEG), and International Journal of EGovernment Research (IJEGR). He is Conference Chair of IFIP EGOV conference series and is chairing mini-tracks at the DG.o, ICEGOV, HICCS, ICIS and AMCIS conferences. He was ranked as one of the leading e-government researchers in a survey in 2009, 2014, and 2016 and has published over 400 refereed publications. More information: www.tbm. tudelft.nl/marijnj.

Nripendra P. Rana is an Associate Professor in the School of Management at Swansea University in the UK. With an academic and professional background in Mathematics and Computer Science and with a $\mathrm{PhD}$ in Information Systems, his current research interests focus primarily upon adoption of emerging and cutting-edge technology in general and e-government, m-government, e-commerce and m-commerce systems in particular. His work has been published in leading academic journals such as European Journal of Marketing, Information Systems Frontiers, Government Information Quarterly, Production Planning \& Control and Computers in Human Behavior.

Emma L. Slade is a Lecturer in Management at the University of Bristol, $\mathrm{UK}$. She has a PhD and MSc with distinction in Business Management. Emma's research and teaching interests revolve around digital technologies and consumer behaviour. Emma has published articles in several highly regarded journals such as Psychology \& Marketing, Computers in Human Behavior, Information Systems Frontiers, Public Management Review, and Journal of Computer Information Systems. In 2016 Emma was selected to participate in CHERISH-DE's inaugural Digital Economy Crucible funded by the EPSRC and in 2017 was selected to participate in a workshop on Fintech Research in Emerging Economies under the British Council's Researcher Links scheme offered within the Newton Fund. Emma was also Programme Co-Chair of the 15th IFIP I3E Conference on Social Media: The Good, the Bad, and the Ugly.

Marc Clement is a full Professor and the Head of School of Management in Swansea University, Chairman of Swansea University's Network/ Relationship Science Analytics Programme and a member of the Advisory Board for the IBM Network Science Research Centre (NSRC). He graduated with a First Class Honours degree in Physics from Swansea University and a $\mathrm{PhD}$ in Laser Physics from Swansea University with the research undertaken at the Rutherford Laboratory. Marc then gained a fellowship from the Royal Society to study at the Centre d'etudes Nucléaires de Saclay, in Paris. He has held several senior academic positions and is currently Executive Chairman in the Institute of Life Science at the College of Medicine, Swansea University. As well as being an eminent academic, Marc is an attempted entrepreneur having founded several businesses and is the named inventor of many patents in the field of medical devices. Marc has also developed a number of projects and initiatives in supercomputing and big data. Marc was a Founding Director of High Performance Computing Wales and established the original Blue $\mathrm{C}$ supercomputer at the Institute of Life Science, Swansea University. Marc has supervised dozens of research degrees and is particularly keen to apply the latest developments in Network and Relationship Science to the Medical profession for the improvement of human health and the development of knowledge economies globally. 